\title{
Intact Insulin Stimulation of Skeletal Muscle Blood Flow, Its Heterogeneity and Redistribution, but Not of Glucose Uptake in Non-insulin-dependent Diabetes Mellitus
}

\author{
Tapio Utriainen, ${ }^{\star \star}$ Pirjo Nuutila, ${ }^{\ddagger}$ Teemu Takala, ${ }^{\star}$ Paolo Vicini, ${ }^{\star \star}$ Ulla Ruotsalainen, ${ }^{*}$ Tapani Rönnemaa, ${ }^{\ddagger}$ Tuula Tolvanen, ${ }^{*}$ \\ Maria Raitakari, $\$$ Merja Haaparanta, " Olli Kirvelä, Claudio Cobelli,

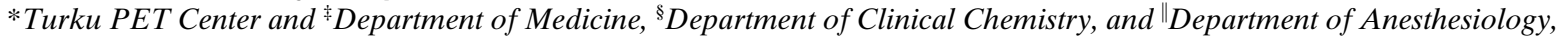 \\ ${ }^{\mathbb{T}}$ Radiochemistry Laboratory, University of Turku, Turku, Finland; **Department of Medicine, Division of Endocrinology and Diabetology, \\ University of Helsinki, Helsinki, Finland; and ${ }^{\ddagger}$ Department of Electronics and Informatics, University of Padova, Padova, Italy
}

\begin{abstract}
We tested the hypothesis that defects in insulin stimulation of skeletal muscle blood flow, flow dispersion, and coupling between flow and glucose uptake contribute to insulin resistance of glucose uptake in non-insulin-dependent diabetes mellitus (NIDDM). We used positron emission tomography combined with $\left[{ }^{15} \mathrm{O}\right] \mathrm{H}_{2} \mathrm{O}$ and $\left[{ }^{18} \mathrm{~F}\right]$-2-deoxy-D-glucose and a Bayesian iterative reconstruction algorithm to quantitate mean muscle blood flow, flow heterogeneity, and their relationship to glucose uptake under normoglycemic hyperinsulinemic conditions in 10 men with NIDDM $\left(\mathrm{HbA}_{1 \mathrm{c}}\right.$ $8.1 \pm 0.5 \%$, age $43 \pm 2 \mathrm{yr}$, BMI $27.3 \pm 0.7 \mathrm{~kg} / \mathrm{m}^{2}$ ) and in 7 matched normal men. In patients with NIDDM, rates of whole body ( $35 \pm 3$ vs. $44 \pm 3 \mu \mathrm{mol} / \mathrm{kg}$ body weight $\cdot \mathrm{min}, P<$ $0.05)$ and femoral muscle $(71 \pm 6$ vs. $96 \pm 7 \mu \mathrm{mol} / \mathrm{kg}$ muscle-min, $P<0.02$ ) glucose uptake were significantly decreased. Insulin increased mean muscle blood flow similarly in both groups, from $1.9 \pm 0.3$ to $2.8 \pm 0.4 \mathrm{ml} / 100 \mathrm{~g}$ muscle.min in the patients with NIDDM, $P<0.01$, and from $2.3 \pm 0.3$ to $3.0 \pm 0.3 \mathrm{ml} / 100 \mathrm{~g}$ muscle-min in the normal subjects, $\boldsymbol{P}<0.02$. Pixel-by-pixel analysis of flow images revealed marked spatial heterogeneity of blood flow. In both groups, insulin increased absolute but not relative dispersion of flow, and insulin-stimulated but not basal blood flow colocalized with glucose uptake. These data provide the first evidence for physiological flow heterogeneity in human skeletal muscle, and demonstrate that insulin increases absolute but not relative dispersion of flow. Furthermore, insulin redirects flow to areas where it stimulates glucose uptake. In patients with NIDDM, these novel actions of insulin are intact, implying that muscle insulin resistance can be attributed to impaired cellular glucose uptake. $(J$. Clin. Invest. 1997. 100:777-785.) Key words: insulin resistance $\bullet$ positron emission tomography $\bullet$ blood flow heterogeneity
\end{abstract}

Address correspondence to Hannele Yki-Järvinen, M.D., Department of Medicine, Division of Endocrinology and Diabetology, University of Helsinki, Haartmaninkatu 4, FIN-00290 Helsinki, Finland. Phone: 358-9-471-2350; FAX: 358-9-471-2250; E-mail: ykijarvi@hel sinki.fi

Received for publication 11 February 1997 and accepted in revised form 15 May 1997.

J. Clin. Invest.

(c) The American Society for Clinical Investigation, Inc. 0021-9738/97/08/0777/09 \$2.00

Volume 100, Number 4, August 1997, 777-785

http://www.jci.org

\section{Introduction}

Resistance to the effect of insulin to increase glucose uptake in skeletal muscle characterizes patients with non-insulin-dependent diabetes mellitus (NIDDM) $(1,2)$. In limb catheterization studies, reduced glucose uptake in NIDDM commonly has been attributed to a defect in glucose extraction (2-5). On the other hand, defects in insulin-induced vasodilation have also been suggested to contribute to insulin resistance in NIDDM (6). The latter studies have been performed under intravenously maintained normoglycemic hyperinsulinemic (clamp) conditions, where the insulin concentrations have been either in the high physiological $(2,4,5)$ or supraphysiological (6) range. Under physiological hyperglycemic hyperinsulinemic conditions after an oral glucose load or a meal $(7,8)$, as well as in the basal state $(7,9)$, the absolute rates of glucose uptake (7-9) and blood flow are normal $(9,10)$, possibly because hyperglycemia compensates for defects in blood flow $(11,12)$ or glucose extraction $(13,14)$. The reason for the discrepant results regarding insulin stimulation of blood flow is unclear.

In previous human studies, mean limb blood flows have been measured using techniques such as plethysmography (4, $14-17)$, thermo- $(6,18)$ and dye- $(2,19)$ dilution, and more recently, $\left[{ }^{15} \mathrm{O}\right] \mathrm{H}_{2} \mathrm{O}$ and positron emission tomography (PET) (20-22). Measurement of mean blood flow does not, however, provide any information of functional or anatomical blood flow heterogeneity, for which there is considerable evidence from studies performed in experimental animals using the microsphere method (23-26). The possibility to distinguish between mean flow and flow distribution (flow heterogeneity) is of importance since it is possible to alter capillary perfusion heterogeneity while maintaining constant mean flow $(27,28)$. Thus, the effect of vasoactive agents such as insulin on oxygen and glucose uptake may depend on their effect on flow heterogeneity rather than total flow (28). Redistribution of blood flow in the absence of any increase in mean flow in skeletal muscle has been found to regulate oxygen delivery during electrical stimulation (29). Interventions including exercise (23), electrical nerve stimulation $(26,30,31)$, and infusion of papaverine (25) or adenosine (30) increase average blood flow and its absolute dispersion (defined as the SD of blood flow), while relative flow dispersion (coefficient of variation, i.e., $\mathrm{SD}$ /

1. Abbreviations used in this paper: FBP, filtered back-projection; $\left[{ }^{18} \mathrm{~F}\right] \mathrm{FDG},\left[{ }^{18} \mathrm{~F}\right]$-2-fluoro-2-deoxy-D-glucose; MRP method, Bayesian reconstruction algorithm that uses median root prior; NIDDM, noninsulin-dependent diabetes mellitus; PET, positron emission tomography; ROI, region of interest. 
mean flow), a measure that is independent of units and mean flow, remains unchanged (27).

In addition to anatomical heterogeneity, skeletal muscle blood flow appears to be functionally heterogenous (28). Although anatomical arteriovenous shunts (allowing passage of $12-\mu \mathrm{m}$ microspheres through the rat hindlimb) do not exist (28), there is evidence for a bimodal distribution of capillary diameters with modes at 5.5 and $7.5 \mu \mathrm{m}$ in rat gastrocnemius muscle, for existence of high- and low-flow capillaries in rabbit vastus lateralis muscle (29), and for functional arteriovenous shunting $(32,33)$. In the isolated perfused, but not in the isolated incubated rat skeletal muscle, insulin resistance can be induced by vasoactive agents, which have been proposed to induce vasoconstriction at sites controlling perfusion to nutritive capillaries, but not by equipotent vasoconstrictors that act at sites controlling nonnutritive flow $(33,34)$. No data are presently available regarding the effect of insulin on skeletal muscle blood flow distribution in humans or animals. It is therefore also unknown whether insulin resistance in patients with NIDDM might affect the ability of insulin to change blood flow distribution or its possible regional coupling to glucose uptake in skeletal muscle. Such knowledge would help to establish whether design of pharmacological agents aimed at improving glucose delivery to muscle in patients with NIDDM has a pathophysiologic basis.

Recent refinements in the technique to measure blood flow using $\left[{ }^{15} \mathrm{O}\right] \mathrm{H}_{2} \mathrm{O}$ and PET in skeletal muscle (35) enabled us to perform reliable pixel-by-pixel quantitation of regional muscle blood flow and analysis of its absolute and relative dispersion. In this study, we used this technique together with $\left[{ }^{18} \mathrm{~F}\right]-2$-fluoro-2-deoxy-D-glucose $\left(\left[{ }^{18} \mathrm{~F}\right] \mathrm{FDG}\right)$ for quantitation of regional glucose uptake to determine $(a)$ whether blood flow is heterogeneously distributed in normal subjects; $(b)$ whether blood flow distribution is altered in patients with NIDDM; $(c)$ whether insulin changes relative flow dispersion in normal subjects; $(d)$ whether this action of insulin is altered in NIDDM; and $(e)$ whether insulin action on muscle blood flow and glucose uptake are coupled regionally. Our results provide the first evidence for physiological flow heterogeneity in human skeletal muscle, and demonstrate an increase in absolute, but not relative dispersion of flow by insulin, and regional coupling of insulin-stimulated but not basal blood flow with glucose uptake. In patients with NIDDM, impaired cellular glucose uptake is responsible for insulin resistance since insulin's effects on mean muscle blood flow and flow dispersion, and redirection of flow to regions using glucose by insulin are intact.

\section{Methods}

\section{Subjects}

10 men with NIDDM and 7 normal men volunteered for the study. All patients with NIDDM were normotensive, and had no clinical or laboratory evidence of diseases other than NIDDM. Physical characteristics of the subjects are shown in Table I. The patients did not have signs or symptoms of retinopathy, neuropathy, or macrovascular disease. One patient with NIDDM had microalbuminuria. Four of the patients were treated with diet alone, while six patients were treated with sulfonylureas and/or metformin. Oral antidiabetic drugs were discontinued for $2 \mathrm{~d}$ before the studies. The duration of NIDDM averaged $3 \pm 1$ yr. The normal subjects were healthy as judged by history, physical examination, and routine laboratory tests, and were not taking any medications. Written informed consent was obtained after the purpose, nature, and potential risks were explained
Table I. Characteristics of the Study Groups

\begin{tabular}{lcc}
\hline & NIDDM & Normal subjects \\
\hline & $n=10$ & $n=7$ \\
Age $(\mathrm{yr})$ & $43 \pm 2$ & $47 \pm 2$ \\
Weight $(\mathrm{kg})$ & $84.7 \pm 3.1$ & $83.4 \pm 1.4$ \\
Height $(\mathrm{cm})$ & $176 \pm 2$ & $180 \pm 2$ \\
Body mass index $\left(\mathrm{kg} / \mathrm{m}^{2}\right)$ & $27.3 \pm 0.7$ & $25.9 \pm 0.6$ \\
Fasting plasma glucose $(\mathrm{mmol} / \mathrm{liter})$ & $8.3 \pm 0.5$ & $5.4 \pm 0.1^{\ddagger}$ \\
Fasting serum insulin $(\mathrm{pmol} / \mathrm{liter})$ & $73 \pm 24$ & $34 \pm 7^{*}$ \\
Glycosylated hemoglobin $\mathrm{A}_{1 \mathrm{c}}(\%)$ & $8.1 \pm 0.5$ & $5.4 \pm 0.3^{\ddagger}$ \\
Systolic blood pressure $(\mathrm{mmHg})$ & $126 \pm 4$ & $124 \pm 4$ \\
Diastolic blood pressure $(\mathrm{mmHg})$ & $84 \pm 4$ & $83 \pm 2$ \\
& & \\
\hline
\end{tabular}

${ }^{*} P<0.05,{ }^{\ddagger} P<0.001$.

to the subjects. The experimental protocol was reviewed and approved by the Ethical Committee of the Turku University Central Hospital.

\section{Study design}

All subjects fasted overnight for 10-12 $\mathrm{h}$ before the studies. Two catheters were inserted; one in an antecubital vein for infusion of glucose and insulin and injection of $\left[{ }^{15} \mathrm{O}\right] \mathrm{H}_{2} \mathrm{O}$ and $\left[{ }^{18} \mathrm{~F}\right] \mathrm{FDG}$, and one in the opposite radial or brachial artery for blood sampling. The patients with NIDDM were rendered normoglycemic before start of the study by using a low-dose insulin infusion according to the algorithm described by Mokan et al. (36). The study for each subject consisted of a 30-min basal period ( -30 to $0 \mathrm{~min}$ ), and a $160-\mathrm{min}(0-160 \mathrm{~min})$ hyperinsulinemic period. Whole body glucose uptake was determined independently of the PET measurements using the euglycemic hyperinsulinemic clamp technique. Muscle blood flow in the femoral region was measured twice, once during the basal period, and once after 60 min of hyperinsulinemia using $\left[{ }^{15} \mathrm{O}_{3} \mathrm{H}_{2} \mathrm{O}\right.$ and PET. Femoral muscle glucose uptake was measured immediately after the blood flow measurement using $\left[{ }^{18} \mathrm{~F}\right] \mathrm{FDG}$ and PET.

\section{Whole body glucose uptake}

Whole body glucose uptake was quantitated using the euglycemic hyperinsulinemic clamp technique (37). After the basal blood flow measurement, serum insulin was increased for 160 min using a primed continuous ( $5 \mathrm{mU} / \mathrm{kg} \cdot \mathrm{min}$ ) insulin infusion (Velosulin; Novo Nordisk A/S, Bagsvaerd, Denmark). Normoglycemia was maintained using an infusion of $20 \%$ glucose. As hepatic glucose production is completely suppressed during a $5 \mathrm{mU} / \mathrm{kg} \cdot \mathrm{min}$ insulin infusion $(38,39)$, whole body glucose uptake was calculated from the glucose infusion rate (during 60-160 min) after correction for changes in the glucose pool size (37). Arterial blood samples were taken at 5-10-min intervals for the determination of plasma glucose, and at 30-min intervals for measurement of the serum free insulin concentrations.

\section{Measurement of muscle blood flow and glucose uptake} with PET

For the flow studies, $\sim 30 \mathrm{mCi}(1.1 \mathrm{GBq})\left[{ }^{15} \mathrm{O}\right] \mathrm{H}_{2} \mathrm{O}$ was injected intravenously, and a dynamic scan was performed for 6 min $(6 \times 5-, 6 \times$ $15-$, and $8 \times 30$-s frames). To obtain the input function, arterial blood was continuously withdrawn with a pump at a speed of $6 \mathrm{ml} / \mathrm{min}$, and the radioactivity concentration was measured using a two-channel online detector system (Scanditronix, Uppsala, Sweden) that was cross-calibrated with an automatic gamma counter (Wizard $14803^{\prime \prime}$; Wallac, Turku, Finland) and the PET scanner.

For the $\left[{ }^{18} \mathrm{~F}\right] \mathrm{FDG}$ study, $\sim 5 \mathrm{mCi}(185 \mathrm{MBq})$ of $\left[{ }^{18} \mathrm{~F}\right] \mathrm{FDG}$ was injected intravenously over $2 \mathrm{~min}$, and a dynamic scan for $90 \mathrm{~min}$ was started $(12 \times 15-, 4 \times 30-, 3 \times 60-, 1 \times 120$-, and $16 \times 300$-s frames). Blood samples for measurement of plasma radioactivity were with- 
drawn once during each time frame, and the radioactivity was measured with an automatic gamma counter (Wizard $14803^{\prime \prime}$ ).

Production of $\left[{ }^{15} \mathrm{O}\right] \mathrm{H}_{2} \mathrm{O}$ and $\left[{ }^{18} \mathrm{~F}\right] \mathrm{FDG}$. For production of $\left[{ }^{15} \mathrm{O}\right]$ $\left(t_{1 / 2}=123 \mathrm{~s}\right)$, a low-energy deuteron accelerator Cyclone 3 was used (Ion Beam Application Inc., Louvain-la-Neuve, Belgium). $\left[{ }^{15} \mathrm{O} \mathrm{H}_{2} \mathrm{O}\right.$ was produced using a dialysis technique in a continuously working water module $(40)$. $\left[{ }^{18} \mathrm{~F}\right] \mathrm{FDG}\left(t_{1 / 2}=109.8 \mathrm{~min}\right)$ was synthesized with an automatic apparatus as described by Hamacher et al. (41). The specific radioactivity at the end of the synthesis was $2 \mathrm{Ci} / \mu \mathrm{mol}$, and the radiochemical purity exceeded $98 \%$.

Image acquisition and processing. An eight-ring ECAT 931/08tomograph (Siemens/CTI Corp., Knoxville, TN) was used. The scanner has an axial resolution of $6.7 \mathrm{~mm}$ and an in-plane resolution of 6.5 $\mathrm{mm}$ (42). The observed final in-plane resolution was $8 \mathrm{~mm}$. The subject was positioned in the tomograph with the femoral regions in the gantry. Before the emission scan, a transmission scan for the correction of photon attenuation was performed for 15 min with a removable ring source containing ${ }^{68} \mathrm{Ge}$ (total counts $15-30 \times 10^{6}$ in a plane). All data were corrected for deadtime, decay, and measured photon attenuation. Dynamic FDG scans were reconstructed into a $128 \times$ 128 matrix using a Hann filter with a cutoff frequency of 0.5 . In the flow studies we used a recently developed Bayesian iterative reconstruction algorithm using median root prior (the MRP method) with 150 iterations and the Bayesian coefficient 0.3 (35). The pixel-by-pixel inhomogeneity and reconstruction artifacts were defined with a cylindrical phantom in which the relative radioactivity concentrations were chosen to represent the levels in muscle and blood vessels. Inhomogeneity as estimated from the coefficient of variation (\%), averaged $\sim 10 \%$ using the former reconstruction method (filtered back-projection, the FBP method [43]) and $\sim 6 \%$ using the newly developed iterative algorithm (35). An example of a parametric flow image reconstructed using the former algorithm and the iterative algorithm used in the present study is shown in Fig. 1.

Calculation of regional muscle blood flow. The methods to measure blood flow with $\left[{ }^{15} \mathrm{O}\right] \mathrm{H}_{2} \mathrm{O}$ are based on the principle of inert tracer kinetics between blood and tissues (44). It has been shown that kinetics of $\left[{ }^{15} \mathrm{O}\right] \mathrm{H}_{2} \mathrm{O}$ can be modeled mathematically with a single compartment model (45). The autoradiographic method (which has been widely used to solve numerically the flow) was used as previously described in detail $(20,46)$. To obtain the actual input function for the tissue element, internal dispersion from the arteries $(5 \mathrm{~s})$ and external dispersion from the tubing in the blood sampling system $(3 \mathrm{~s})$ were corrected for by using an exponential dispersion function time constant. The delay between the input curve and the tissue curve was solved by fitting. Blood flow was calculated pixel-by-pixel into flow images using a 250-s tissue integration time as previously described (20).

Calculation of regional glucose uptake. We used the three-compartment model of $\left[{ }^{18} \mathrm{~F}\right] \mathrm{FDG}$ kinetics (47) and graphical analysis as previously described (48). Plasma and tissue time-activity curves were analyzed graphically to quantitate the fractional rate of tracer phosphorylation $K_{\mathrm{i}} . \mathrm{K}_{\mathrm{i}}$ is equal to $\left(K_{1} \times k_{3}\right) /\left(k_{2}+k_{3}\right)$, where $K_{1}$ and $k_{2}$ are the transfer coefficients from vascular space into the tissue and back, respectively, and $k_{3}$ is the phosphorylation rate constant. The rate of the glucose uptake (rGU) is obtained by multiplying $K_{\mathrm{i}}$ by the plasma glucose concentration [Glc] divided by a lumped constant term (LC): $r G U=K_{\mathrm{i}} \times\left([G l c]_{\mathrm{p}} / L C\right)$. The lumped constant accounts for differences in the transport and phosphorylation of $\left[{ }^{18} \mathrm{~F}\right] \mathrm{FDG}$ and glucose. The lumped constant value was assumed to equal 1.0 for skeletal muscle as previously described (48).

Regions of interest. Regions of interest (ROIs) were drawn in the anterior, anterolateral, and posterior muscle compartments of the femoral region in four consecutive cross-sectional slices in both legs, carefully avoiding the great vessels. Localization of the muscle compartments was verified by comparison of the flow images with the transmission image, which provides a topographical distribution of tissue density. The ROIs outlined in the flow images were copied to the $\left[{ }^{18} \mathrm{~F}\right] \mathrm{FDG}$ radioactivity images to obtain quantitative data from identical regions.
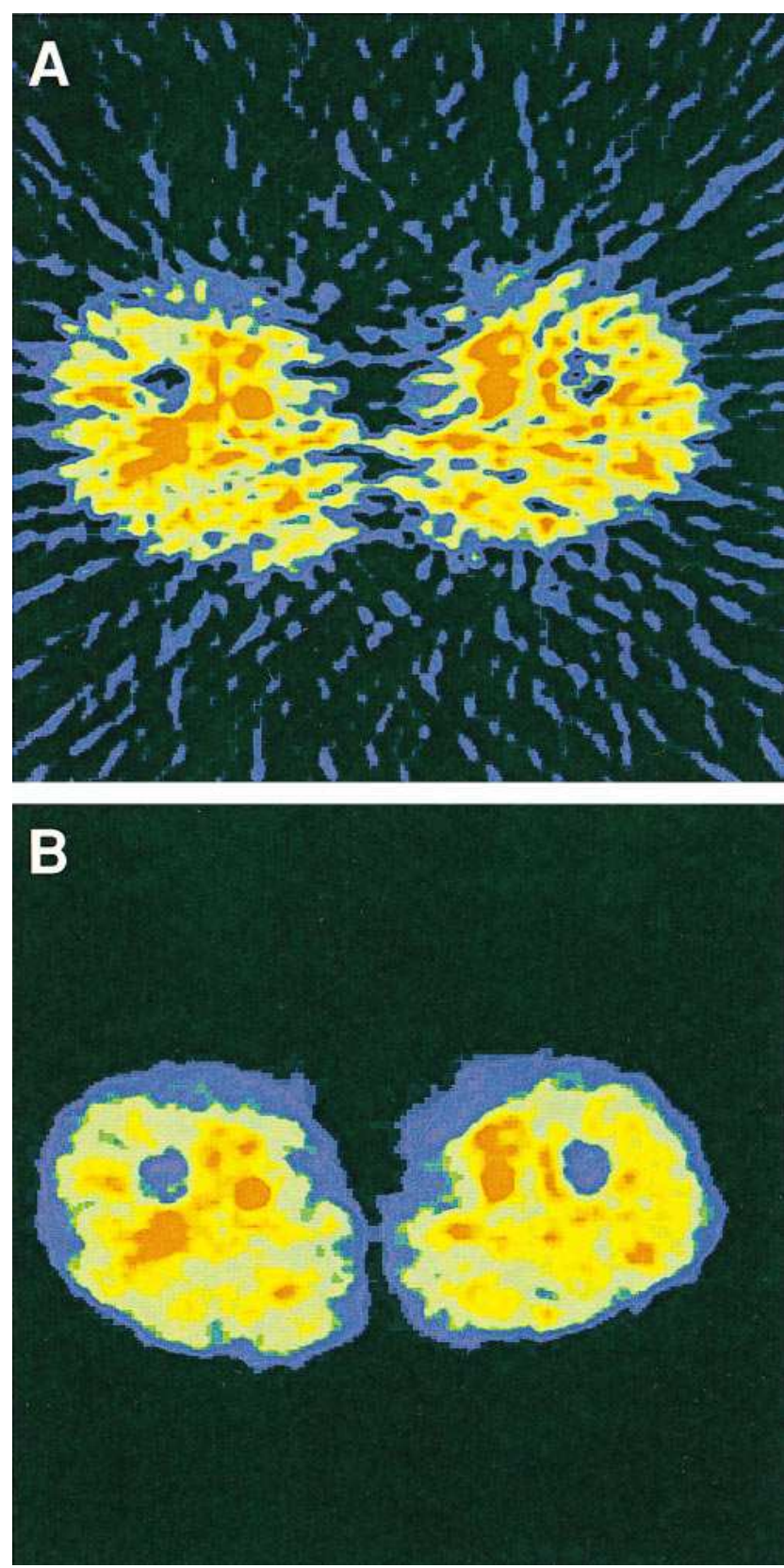

Figure 1. Example of a parametric flow image depicting a cross-section of the femoral region reconstructed using the FBP method $(A)$ and using the MRP method $(B)$.

Regional heterogeneity of blood flow. Blood flow values were extracted from the pixel-by-pixel flow image. A single large ROI drawn onto the muscle area was used for analysis of flow distribution. On the average this ROI consisted of $699 \pm 27$ pixels $\left(62.9 \pm 2.4 \mathrm{~cm}^{2}\right)$. The standard deviation of the flow values was used as an index of absolute flow dispersion. The distributions were normalized with average flow within the ROI to obtain the relative flow distribution. The coefficient of variation of blood flow was calculated by dividing the standard deviation of blood flow by average flow, and was used to characterize relative flow dispersion or true flow heterogeneity $(27,49)$. It is possible that the coefficient of variation remains constant in response to an intervention, while the shape of the distribution changes. The latter would also indicate redistribution of blood flow (27). This pos- 
sibility was evaluated by visually analyzing the shape of histograms depicting the relative flow.

\section{Other measurements}

Blood pressure and heart rate were determined every $30 \mathrm{~min}$ throughout the study using an automatic oscillometric blood pressure analyzer (Omron HEM-705C; Omron Corp., Japan). The concentration of glycosylated hemoglobin in blood was measured by liquid chromatography. Plasma glucose was measured using the glucose oxidase method (Analox GM7 Analyzer; Analox Instruments Ltd., Hammersmith, London, England). Serum free insulin concentrations were measured using a double antibody radioimmunoassay (Pharmacia Insulin RIA kit; Pharmacia Diagnostics AB, Uppsala, Sweden) after precipitation with polyethylene glycol.

\section{Statistical methods}

Differences in paired data were analyzed using the Student's paired $t$ test, and group comparisons were performed with the unpaired Student's $t$ test for normally distributed data. The results are expressed as mean \pm SEM. All statistical analyses were performed using the SYSTAT software (Systat Inc., Evanston, IL).

\section{Results}

Glucose and insulin concentrations, whole body glucose uptake. Fasting plasma glucose and serum free insulin concentrations are given in Table I. During hyperinsulinemia, serum

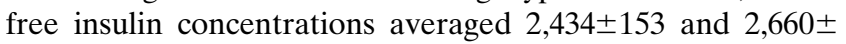
$102 \mathrm{pmol} / \mathrm{liter}$ in the patients with NIDDM and normal subjects (NS), and plasma glucose concentrations averaged $5.3 \pm 0.1$ and $5.3 \pm 0.1 \mathrm{mmol} / \mathrm{liter}$, respectively (NS). Whole body glucose uptake during hyperinsulinemia was significantly lower in the patients with NIDDM $(35 \pm 3 \mu \mathrm{mol} / \mathrm{kg}$ body $\mathrm{wt} \cdot \mathrm{min})$ than in the normal subjects $(44 \pm 3 \mu \mathrm{mol} / \mathrm{kg}$ body wt.min, $P<0.05)$.

Muscle glucose uptake and blood flow. Insulin-stimulated femoral muscle glucose uptake was significantly lower in the patients with NIDDM $(71 \pm 6 \mu \mathrm{mol} / \mathrm{kg}$ muscle $\cdot \min )$ than in the normal subjects $(96 \pm 7 \mu \mathrm{mol} / \mathrm{kg}$ muscle $\cdot \min , P<0.02)$. Femoral muscle blood flow increased during insulin infusion from $1.9 \pm 0.3$ to $2.8 \pm 0.4 \mathrm{ml} / 100 \mathrm{~g}$ muscle $\cdot \min (P<0.01)$ in the patients with NIDDM, and from $2.3 \pm 0.3$ to $3.0 \pm 0.3 \mathrm{ml} / 100 \mathrm{~g}$ muscle $\min (P<0.02)$ in the normal subjects. Neither basal nor insulin-stimulated blood flow was significantly different between groups.

Heterogeneity of blood flow in skeletal muscle. Muscle blood flow showed considerable heterogeneity. Fig. 2 illustrates examples of flow distribution within a large muscle ROI in the basal state and during insulin infusion. Insulin increased both the mean blood flow (vide supra) and the absolute dispersion of flow both in patients with NIDDM $(0.55 \pm 0.10 \mathrm{vs}$. $0.91 \pm 0.15$ $\mathrm{ml} / 100 \mathrm{~g}$ muscle $\cdot \mathrm{min}$, basal vs. insulin, $P<0.05)$ and in normal subjects $(0.72 \pm 0.20$ vs. $0.83 \pm 0.15 \mathrm{ml} / 100 \mathrm{~g}$ muscle $\cdot \mathrm{min}, P<$ $0.05)$. The relative dispersion of blood flow averaged $0.30 \pm$ 0.02 basally and $0.32 \pm 0.03$ during hyperinsulinemia (NS) in patients with NIDDM, and $0.30 \pm 0.03$ and $0.27 \pm 0.02$, respectively (NS), in normal subjects (NS for NIDDM vs. normal subjects). The shape of the distribution of relative blood flow did not change in response to insulin (Fig. 3). We also compared the flow distributions within an ROI traced around the total cross-section of the thigh and an ROI traced within muscle tissue. The frequency of low-flow components was markedly higher in the ROI representing the total cross-section of the thigh as compared to the ROI traced within the muscle tissue (Fig. 4). The low-flow components originated from tissues such as the skin, subcutaneous fat, and bone.

Colocalization of glucose uptake and blood flow. To examine whether there was an association between regional glucose uptake and blood flow, the six ROIs of each subject were first ranked into descending order based on the rate of muscle glucose uptake. Averages of blood flows in these ROIs were then calculated. By definition, glucose uptake rates between these
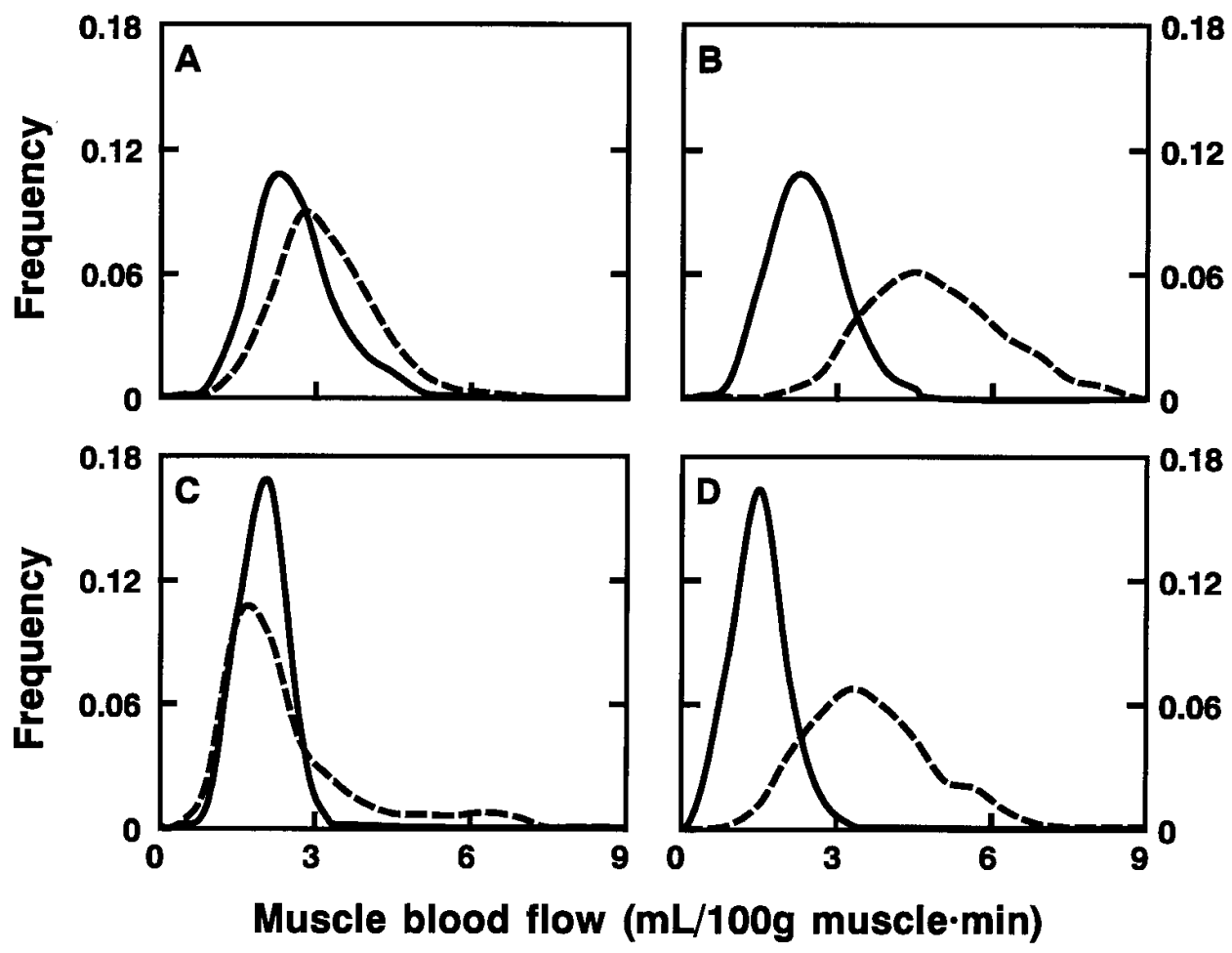

Figure 2. Individual examples of muscle blood flow distributions in the basal state (continuous line) and during hyperinsulinemia (dashed line). $A$ and $B$ depict two normal subjects, and $C$ and $D$ depict two patients with NIDDM. A normal subject with a small change in muscle blood flow (2.6 \pm 0.9 vs. $3.0 \pm 0.9$ $\mathrm{ml} / 100 \mathrm{~g}$ muscle $\cdot \mathrm{min}$, basal vs. insulin) is shown in $A$, and a patient with NIDDM with a small change in flow $(2.0 \pm 0.4$ vs. $2.9 \pm 1.6 \mathrm{ml} / 100 \mathrm{~g}$ muscle $\cdot \min$, respectively) is shown in $C$. A normal subject $(2.2 \pm 0.6$ vs. $4.6 \pm 1.3 \mathrm{ml} / 100 \mathrm{~g}$ muscle $\cdot \mathrm{min}$, basal vs. insulin) and a patient with NIDDM (1.5 \pm 0.4 vs. $3.2 \pm 0.8$ $\mathrm{ml} / 100 \mathrm{~g}$ muscle $\cdot \mathrm{min}$, respectively) demonstrating large increases in muscle blood flow are shown in $B$ and $D$. 

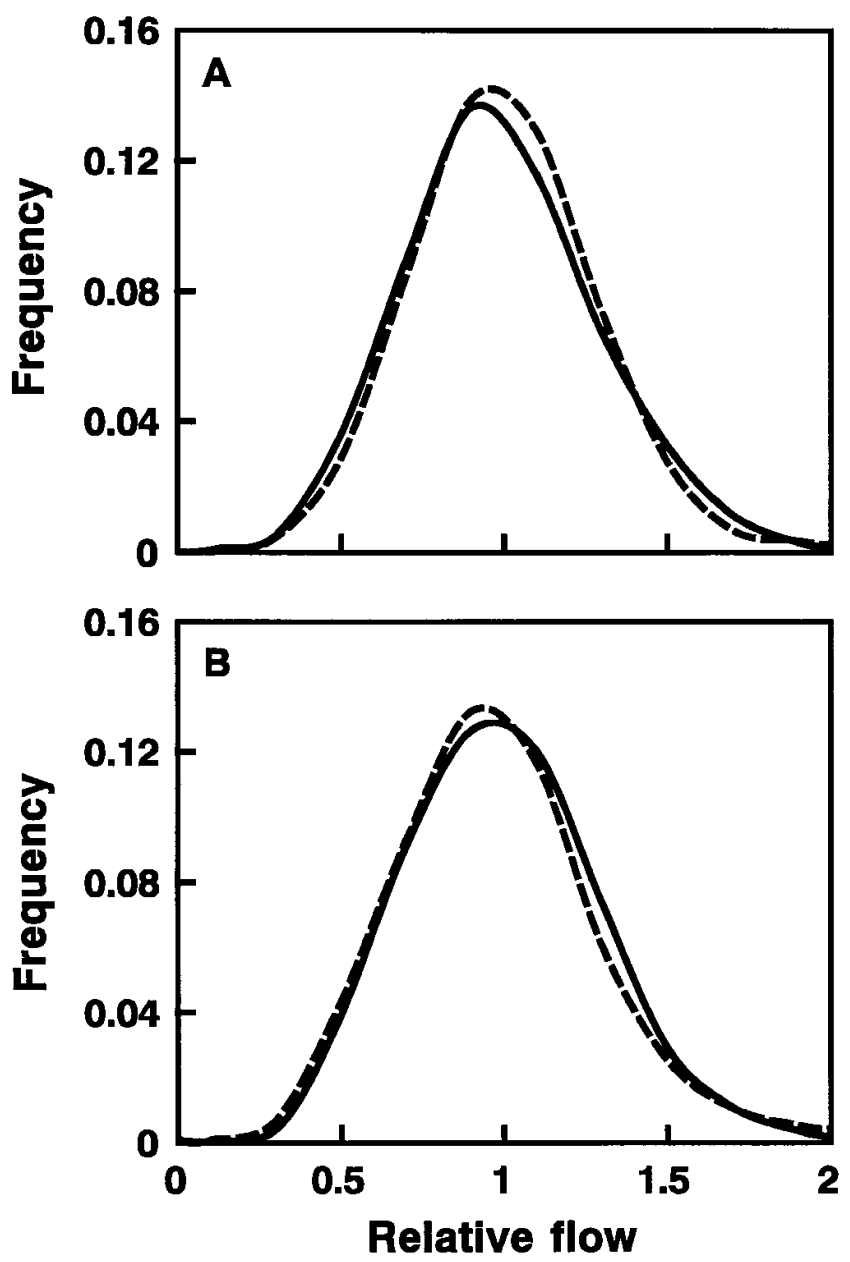

ranked ROIs were significantly different $(P<0.05-0.001$ for all comparisons between ranked ROIs). While the rates of basal blood flow corresponding to these ROIs were evenly distributed between the six ROIs, a difference appeared during insulin infusion (Fig. 5). Insulin-stimulated blood flows were significantly higher in ROIs with high than in those with low glucose uptake rates. The redistribution of blood flow to areas with highest rates of glucose uptake was observed both in the patients with NIDDM and in the normal subjects, although the rate of glucose uptake was significantly lower in all ROIs in the patients with NIDDM than in the normal subjects (Fig. 5).

\section{Discussion}

This study was undertaken to determine in normal subjects and in patients with NIDDM whether blood flow heterogeneity exists in human skeletal muscle, and if so whether the flow distribution changes in response to insulin. We also determined whether insulin redirects blood flow to areas using glucose in normal subjects, and whether this action of insulin is preserved in patients with NIDDM. These analyses were made possible by recent improvements in the technique to measure blood flow with $\left[{ }^{15} \mathrm{O}\right] \mathrm{H}_{2} \mathrm{O}$ and PET. Our results provide the first evidence for flow heterogeneity in human skeletal muscle, and show that insulin increases absolute, but not relative dispersion of flow. Insulin also redirects blood flow to areas where it stimulates glucose uptake. In patients with NIDDM,

Figure 3. Mean relative muscle blood flow distributions in normal subjects $(A)$ and in patients with NIDDM $(B)$ in the basal state (continuous line) and during hyperinsulinemia (dashed line).
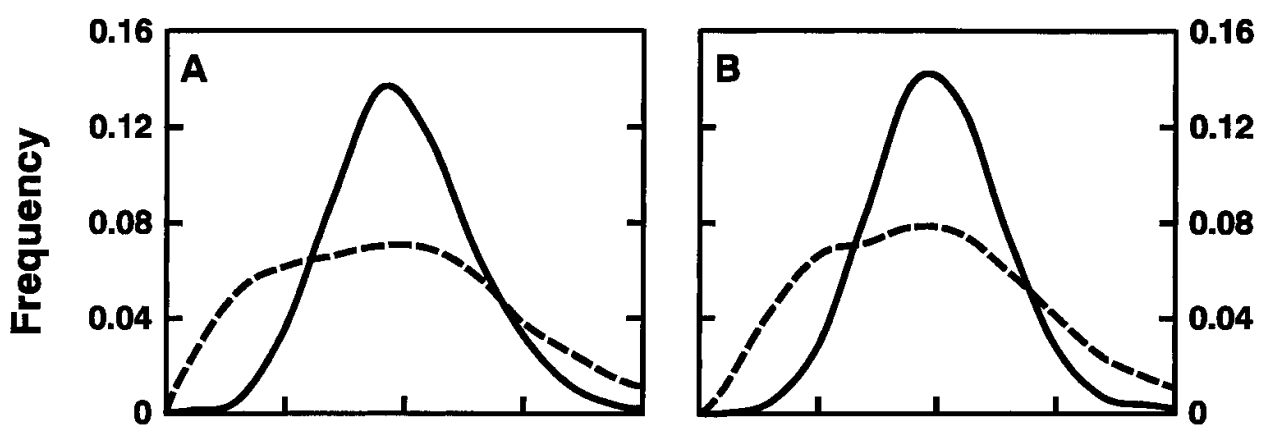

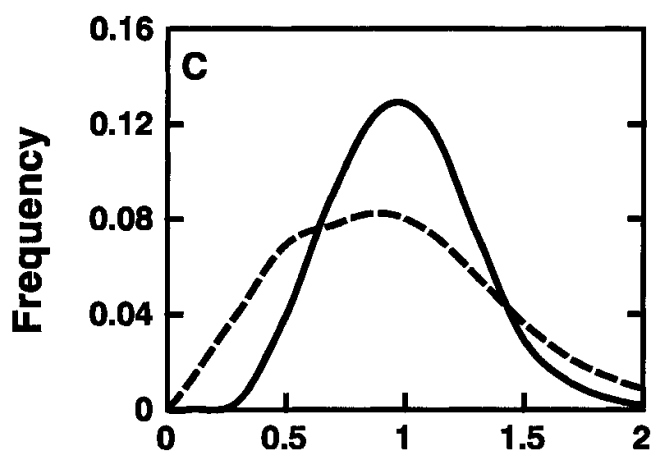

Relative flow

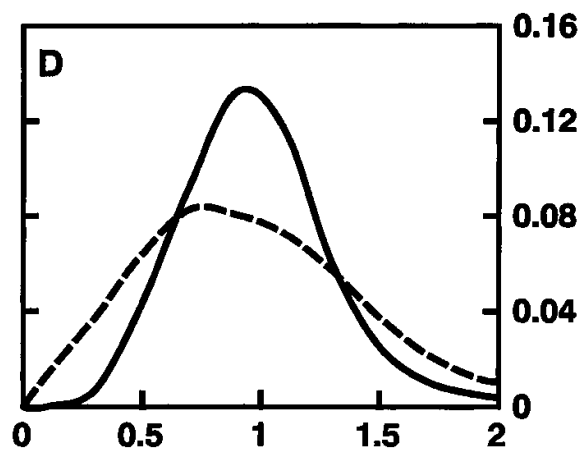

Relative flow
Figure 4. A comparison of the distribution of relative flow in an ROI traced within femoral muscle (continuous line) and a region traced around the entire thigh (dashed line) in the basal state $(A)$ and during hyperinsulinemia $(B)$ in all normal subjects, and in all patients with NIDDM ( $C$ and $D$, respectively). 


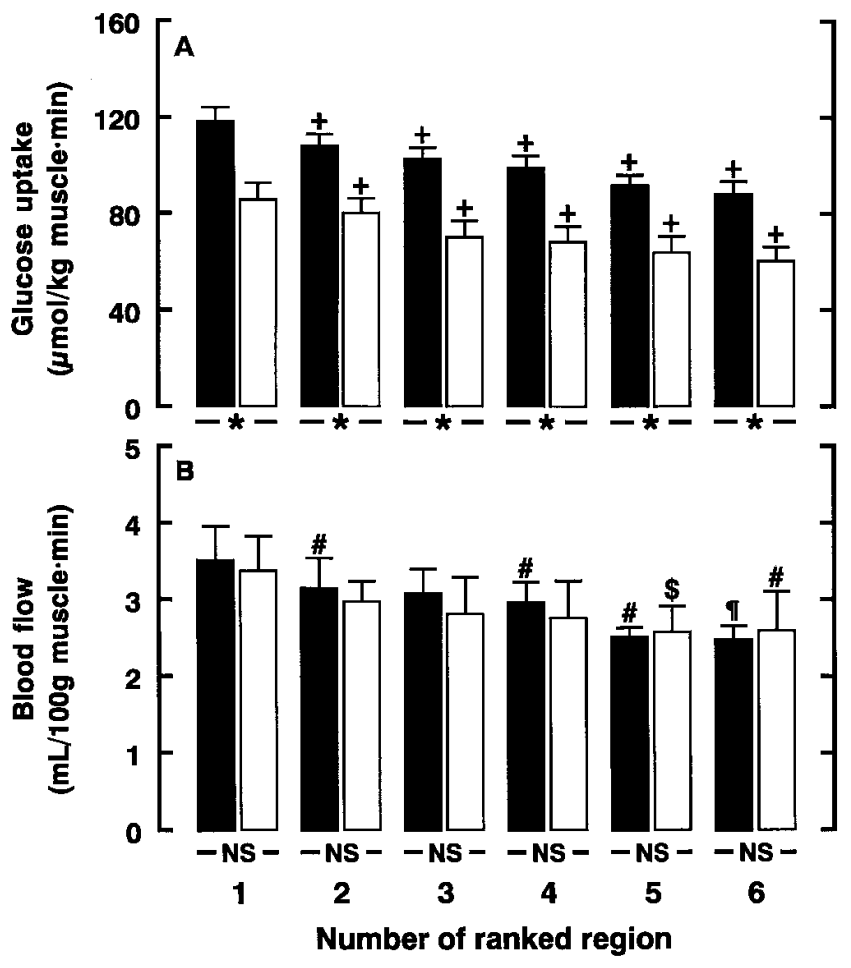

Figure 5. For analysis of colocalization of glucose uptake and blood flow, the six ROIs drawn in the femoral muscle area of each subject were ranked on the basis of the rate of insulin-stimulated glucose uptake. $A$ shows the rates of muscle glucose uptake in descending order $(1=$ region with highest and $6=$ region with lowest rate of glucose uptake) in the normal subjects (closed bars) and in the patients with NIDDM (open bars). $B$ shows insulin-stimulated muscle blood flows in the same regions in the normal subjects (closed bars) and in the patients with NIDDM (open bars). Between groups comparisons: $* P<$ 0.05 . Within group comparisons are as follows: ${ }^{+} P<0.01-0.05$ vs. previous region, ${ }^{\#} P<0.05$ vs. region $1,{ }^{\mathbb{}} P<0.05$ vs. regions 1,3 , and $4,{ }^{\$} P<0.05$ vs. regions 1 and 2 .

cellular glucose uptake is impaired despite normal insulin effects on muscle blood flow, flow dispersion, and redirection of blood flow to glucose-using areas.

Unlike in high-flow regions, in low-flow $(<10 \mathrm{ml} / 100 \mathrm{~g}$ tissue $\min$ ) regions such as resting skeletal muscle, the relationship between tissue radioactivity after a bolus injection of $\left[{ }^{15} \mathrm{O}\right] \mathrm{H}_{2} \mathrm{O}$ and blood flow is linear (20). Therefore, the calculated flow in a measurement volume represents the true average flow in this small area. In the present study, the statistical noise associated with low-flow measurements was reduced both using a long integration time ( $250 \mathrm{~s})$ and using a recently validated iterative reconstruction algorithm $(20,35)$. The MRP method, unlike the FBP method, has been developed for emission studies where radioactivity originates inside the study object. The FBP method, which is still commonly used in PET studies, was originally developed for transmission studies (e.g., computed tomography) where the radioactivity originates outside the study object (43). We used the MRP method in this study because this method allows good noise reduction without compromising spatial resolution (Fig. 1) (35). Reconstruction artifacts were reduced by almost $50 \%$ compared to the FBP method, and we were therefore able to analyze heteroge- neity in blood flow not only between but also within single ROIs. The improved image quality might explain why we have previously been unable to demonstrate colocalization of regional blood flow and glucose uptake (50). Our estimates of the relative dispersion of blood flow $(0.27-0.32)$ are of the same magnitude as previous estimates in studies where heterogeneity has been estimated in animals using labeled microspheres $(27,31)$. For example, in rabbit and cat gastrocnemius muscles, the relative dispersion of spatial blood flows expressed as coefficient of variation has been found to be $0.2-0.6$ depending on the size and number of regions used for analysis (26). The within region variation of flow in the present study is markedly higher than could be expected if the variation was only caused by technical factors such as pixel-by-pixel inhomogeneity (see Methods). Therefore, true spatial variation in perfusion exists within human skeletal muscles.

In the present study, insulin increased absolute dispersion of blood flow while relative dispersion remained unchanged. These data are consistent with previous data demonstrating increases in blood flow by interventions such as exercise $(26,30$, 31 ) or infusion of vasodilating agents such as papaverine (25) or adenosine (30) with no change in relative flow dispersion. Furthermore, in dogs, glucose-insulin-potassium infusions have been shown to increase coronary blood flow, but not flow heterogeneity, as determined from regional blood flows normalized for mean flow (51). It is of interest to note that vasodilation induced by adenosine does not enhance insulin-stimulated glucose uptake in human skeletal muscle (52). Given that insulin appears to have a similar effect on blood flow heterogeneity and distribution as adenosine (30), one might predict that insulin-induced vasodilation does not per se enhance glucose uptake. Such a conclusion is, however, premature at present. First, although animal studies support the view that total flow and flow distribution can be independently controlled $(27,28)$, it is currently unknown how changes in blood flow distribution relate to oxygen consumption and capillary exchange rates of substrates such as glucose in human skeletal muscle. Studies comparing effects of vasoactive agents, which change total flow similarly but have opposite effects on oxygen uptake (28), would need to be undertaken to resolve this issue. In the perfused rat hindlimb, out of 18 agents that change total blood flow similarly, 13 have been found to increase oxygen uptake (type A agents) while 5 (type B agents) had no effect on oxygen uptake (28). Thus, the present study does not allow classification of insulin as a type A or type B agent, but provides the first description of flow heterogeneity in human skeletal muscle and its change in response to insulin.

Regarding previous data reporting mean blood flows in patients with NIDDM, it was believed for many years that a defect in glucose extraction was responsible for insulin resistance in patients with NIDDM (2). The study of Laakso et al. (6) led to reassessment of the possible contribution of defects in blood flow to insulin resistance in patients with NIDDM with negative results $(3-5,15)$. The method or limb used to measure blood flow does not seem to explain the discrepant results, as no defects in blood flow in patients with NIDDM have been reported using dye dilution $(2,5)$, thermodilution $(3,18)$ or venous occlusion plethysmography $(4,15)$ methods across forearm and leg tissues. The effect of insulin on limb blood flow is both time- and concentration-dependent $(53,54)$. The insulin dose in the studies of DeFronzo et al. (2), Mandarino et al. (4), Bak et al. (15), and Bonadonna et al. (5) (1-2 mU/ 
$\mathrm{kg} \cdot \min$ for 2-3 h) was lower than in the study of Laakso et al. (6) (sequential infusions of $3,7.5,15$, and $30 \mathrm{mU} / \mathrm{kg} \cdot \mathrm{min}$ for over $6.5 \mathrm{~h}$ ). One might argue that the duration of the insulin infusion or the dose of insulin was insufficient to increase blood flow in many of the previous studies $(2,4,5,15)$, and that defects were therefore not detected. This seems not to be the case since in normal subjects, Dela et al. $(3,18)$ found an $\sim 55 \%$ increase in leg blood flow during 6-h sequential low- and highdose insulin infusions, and Tack et al. (17) found an $\sim 30 \%$ increase in blood flow after $90 \mathrm{~min}$ of a $1.5 \mathrm{mU} / \mathrm{kg} \cdot \mathrm{min}$ insulin infusion. In keeping with these data, in the present study we observed a $31 \%$ increase in muscle blood flow after $60 \mathrm{~min}$ of a $5 \mathrm{mU} / \mathrm{kg} \cdot \mathrm{min}$ insulin infusion. No defect in insulin stimulation of blood flow was, however, observed in patients with NIDDM in these studies. The NIDDM patients studied by Laakso et al. (6) were slightly more obese (BMI $33 \mathrm{~kg} / \mathrm{m}^{2}$ ) than the obese nondiabetic control subjects $\left(30 \mathrm{~kg} / \mathrm{m}^{2}\right)$, and more obese than the patients studied by Dela et al. (BMI $\left.29 \mathrm{~kg} / \mathrm{m}^{2}\right)(3,18)$ and Tack et al. (BMI $24 \mathrm{~kg} / \mathrm{m}^{2}$ ) (17). This may contribute to the discrepant findings, since obesity independently impairs insulin-induced vasodilation $(53,55)$. The patients studied by Laakso et al. also had worse glycemic control than those in the other studies $(3,17,18)$. Since insulin stimulates blood flow in an endothelium-dependent manner $(56,57)$, and chronic hyperglycemia blunts endothelium-dependent vasodilation (58, 59 ), differences in glycemic control could explain the discrepant findings. In keeping with this, the vasodilatory response to high insulin concentrations is improved by intensive insulin therapy in NIDDM (12).

Our findings extend previous studies by demonstrating that insulin not only increases, but also redistributes blood flow within muscle tissue to the same regions where it stimulates glucose uptake. In rabbits, a positive association between regional muscle glucose uptake and blood flow has been observed during exercise, but not under resting conditions (60). Similarly, insulin-stimulated but not basal blood flow was associated with glucose uptake in the present study. Since it is not technically feasible to perform pixel-by-pixel quantitation of glucose uptake, colocalization of blood flow and glucose uptake was analyzed in three ROIs per limb, which might miss out on putative differences in the coupling efficiency between insulin-stimulated blood flow and glucose uptake in normal subjects as compared to patients with NIDDM. This seems unlikely, however, since significant coupling was observed within both groups, even though large ROIs were used for analysis (Fig. 5), and since pixel analyses of blood flow were identical in both groups. In rats, muscles with the highest proportion of oxidative type I muscle fibers have the highest rates of blood flow (61). In rats, however, several muscles have distinct morphology, i.e., fiber type and capillarization, whereas in humans all femoral muscles consist of mixtures of various fiber types. For example, the flexor and extensor muscles of the knee contain roughly equal proportions of type I and type II fibers $(62,63)$. It is therefore not possible to analyze ROIs within femoral muscles with respect to the ability of different muscle fiber types to use glucose. Oxidative type I fibers are more sensitive to insulin, and are surrounded by more capillaries than type IIb fibers (64-66). Muscle capillarization, as estimated from the capillaries per fiber ratio, is positively correlated with insulin-stimulated blood flow across the limb (67). Therefore, modest differences in muscle morphology between the ROIs may explain the colocalization of insulin-stimulated blood flow and glucose uptake in the present study. Alternatively, the rate of glucose metabolism could be the signal for the observed increase in flow. This possibility seems unlikely for two reasons. First, previous studies have shown that insulin rather than the rate of glucose metabolism determines the magnitude of insulin-induced vasodilation $(14,68)$. Second, in the present study blood flow increased similarly in both normal subjects and patients with NIDDM, although the latter group had a reduced rate of glucose metabolism.

Regarding the location of the defect in cellular glucose extraction in patients with NIDDM, some investigators have used a three-compartment model for $\left[{ }^{18} \mathrm{~F}\right] \mathrm{FDG}$ tissue activity to derive rate constants of $\left[{ }^{18} \mathrm{~F}\right] \mathrm{FDG}$ transport and phosphorylation in skeletal muscle $(69,70)$. Such analysis could also be performed on the present $\left[{ }^{18} \mathrm{~F}\right] \mathrm{FDG}$ activity data. However, we chose not to do this for several reasons. Most importantly, the rate constants for glucose transport and phosphorylation have only been validated for use in the brain (47). As brain glucose uptake differs from skeletal muscle glucose uptake in many respects such as insulin dependency (71) and the enzymatic isoforms responsible for glucose transport and phosphorylation $(72,73)$, we feel that the compartmental model providing transport and phosphorylation parameters needs to be validated before its use in skeletal muscle. Furthermore, quantitation of glucose fluxes using different tracers for measurement of glucose transport (3-O- $\left[{ }^{14} \mathrm{C}\right]$ methyl-D-glucose), phosphorylation and subsequent glucose metabolism (D- $\left[3-{ }^{3} \mathrm{H}\right]$ glucose) and the extracellular space (D-mannitol), have indicated that the intracellular glucose concentration changes during insulin stimulation $(5,74)$. This implies that even if the rate constants could be determined, the actual rates of glucose transport and phosphorylation would still remain unknown.

In conclusion, high insulin concentrations increase muscle blood flow and the absolute, but not relative, dispersion of flow. Insulin not only increases muscle blood flow, but also redistributes flow preferentially to areas with high rates of glucose uptake. This suggests that at least regionally, the metabolic and hemodynamic effects of insulin are coupled. Functional coupling appears unlikely, however, since integrity of the hemodynamic effects of insulin do not overcome cellular insulin resistance in NIDDM.

\section{Acknowledgments}

We thank Vesa Oikonen, Mika Teräs, Hannu Sipilä, Mika Klemetsö, the nurses of the Turku PET Center for skillful technical assistance, and Soile Aarnio for drawing the figures.

This study was supported by grants from the Academy of Finland (H. Yki-Järvinen), the Sigrid Juselius (H. Yki-Järvinen) and Ahokas (H. Yki-Järvinen and P. Nuutila) foundations, the Research Foundation of Orion Corporation (T. Utriainen), and the M.D./Ph.D. Program of the University of Helsinki (T. Utriainen).

\section{References}

1. Kolterman, O.G., R.S. Gray, J. Griffin, P. Burstein, J. Insel, J.A. Scarlett, and J.M. Olefsky. 1981. Receptor and postreceptor defects contribute to the insulin resistance in non-insulin-dependent diabetes mellitus. J. Clin. Invest. 68: 957-969.

2. DeFronzo, R.A., R. Gunnarsson, O. Björkman, M. Olsson, and J. Wahren. 1985. Effects of insulin on peripheral and splanchnic glucose metabolism in non-insulin-dependent (type II) diabetes mellitus. J. Clin. Invest. 76: 149-155.

3. Dela, F., J.J. Larsen, K.J. Mikines, T. Ploug, L.N. Petersen, and H. Galbo. 
1995. Insulin-stimulated muscle glucose clearance in patients with NIDDM. Effects of one-legged physical training. Diabetes. 44:1010-1020.

4. Mandarino, L.J., A. Consoli, A. Jain, and D.E. Kelley. 1996. Interaction of carbohydrate and fat fuels in human skeletal muscle: impact of obesity and NIDDM. Am. J. Physiol. 270:E463-E470.

5. Bonadonna, R.C., S. Del Prato, E. Bonora, M.P. Saccomani, G. Gulli, A. Natali, S. Frascerra, N. Pecori, E. Ferrannini, D. Bier, et al. 1996. Roles of glucose transport and glucose phosphorylation in muscle insulin resistance of NIDDM. Diabetes. 45:915-925.

6. Laakso, M., S.V. Edelman, G. Brechtel, and A.D. Baron. 1992. Impaired insulin-mediated skeletal muscle blood flow in patients with NIDDM. Diabetes. 41:1076-1083.

7. Firth, R.G., P.M. Bell, H.M. Marsh, I. Hansen, and R.A. Rizza. 1986. Postprandial hyperglycemia in patients with non-insulin-dependent diabetes mellitus. Role of hepatic and extrahepatic tissues. J. Clin. Invest. 77:1525-1532.

8. Mitrakou, A., D. Kelley, T. Veneman, T. Jenssen, T. Pangburn, J. Reilly, and J. Gerich. 1990. Contribution of abnormal muscle and liver glucose metabolism to postprandial hyperglycemia in NIDDM. Diabetes. 39:1381-1390.

9. Gerich, J.E., A. Mitrakou, D. Kelley, L. Mandarino, N. Nurjhan, T. Jenssen, T. Veneman, and A. Consoli. 1990. Contribution of impaired muscle glucose clearance to reduced postabsorptive systemic glucose clearance in NIDDM. Diabetes. 39:211-216.

10. Butterfield, W.J.H., and M.J. Whichelow. 1965. Peripheral glucose metabolism in control subjects and diabetic patients during glucose, glucose-insulin and insulin sensitivity tests. Diabetologia. 1:43-53.

11. Baron, A.D., M. Laakso, G. Brechtel, and S.V. Edelman. 1991. Mechanism of insulin resistance in insulin-dependent diabetes mellitus: a major role for reduced skeletal muscle blood flow. J. Clin. Endocrinol. Metab. 73:637-643.

12. Baron, A.D., M. Laakso, G. Brechtel, and S.V. Edelman. 1991. Reduced capacity and affinity of skeletal muscle for insulin-mediated glucose uptake in non-insulin-dependent diabetic subjects. J. Clin. Invest. 87:1186-1194.

13. Yki-Järvinen, H., A.A. Young, C. Lamkin, and J.E. Foley. 1987. Kinetics of glucose disposal in whole body and across the forearm in man. J. Clin. Invest. 79:1713-1719.

14. Mäkimattila, S., A. Virkamäki, R. Malmström, T. Utriainen, and H. Yki-Järvinen. 1996. Insulin resistance in type 1 diabetes mellitus: a major role for reduced glucose extraction. J. Clin. Endocrinol. Metab. 81:707-712.

15. Bak, J.F., N. Møller, O. Schmitz, A. Saaek, and O. Pedersen. 1992. In vivo insulin action and muscle glycogen synthase activity in type 2 (non-insulindependent) diabetes mellitus: effects of diet treatment. Diabetologia. 35:777784.

16. Ebeling, P., J.A. Tuominen, R. Bourey, L. Koranyi, and V.A. Koivisto. 1995. Athletes with IDDM exhibit impaired metabolic control and increased lipid utilization with no increase in insulin sensitivity. Diabetes. 44:471-477.

17. Tack, C.J.J., P. Smits, J.J. Willemsen, J.W.M. Lenders, T. Thien, and J.A. Lutterman. 1996. Effects of insulin on vascular tone and sympathetic nervous system in NIDDM. Diabetes. 45:15-22.

18. Dela, F., J.J. Larsen, K.J. Mikines, and H. Galbo. 1995. Normal effect of insulin to stimulate leg blood flow in NIDDM. Diabetes. 44:221-226.

19. Andres, R., K.L. Zierler, H.M. Anderson, W.N. Stainsby, G. Cader, A.S. Ghrayyib, and J.L. Lilienthal, Jr. 1954. Measurement of blood flow and volume in the forearm of man, with notes on the theory of indicator dilution and on production of turbulence, hemolysis, and vasodilatation by intravascular injection. J. Clin. Invest. 33:482-504.

20. Ruotsalainen, U., M. Raitakari, P. Nuutila, V. Oikonen, H. Sipilä, M. Teräs, M.J. Knuuti, P.M. Bloomfield, and H. Iida. 1997. Quantitative blood flow measurement of skeletal muscle using oxygen-15-water and PET. J. Nucl. Med. 38:314-319.

21. Nuutila, P., M. Raitakari, H. Laine, O. Kirvelä, T. Takala, T. Utriainen, S. Mäkimattila, O.-P. Pitkänen, U. Ruotsalainen, H. Iida, et al. 1996. Role of blood flow in regulating insulin-stimulated glucose uptake in humans. Studies using bradykinin, $\left[{ }^{15} \mathrm{O}\right]$ water, and $\left[{ }^{18} \mathrm{~F}\right]$ fluoro-deoxy-glucose and positron emission tomography. J. Clin. Invest. 97:1741-1747.

22. Raitakari, M., P. Nuutila, U. Ruotsalainen, M. Teräs, E. Eronen, H. Laine, O.T. Raitakari, H. Iida, M.J. Knuuti, and H. Yki-Järvinen. 1996. The relationship between limb and muscle blood flow in man. J. Physiol. 469:543-549.

23. Armstrong, R.B., and M.H. Laughlin. 1983. Blood flows within and among rat muscles as a function of time during high speed treadmill exercise. $J$. Physiol. 344:189-208.

24. Pendergast, D.R., J.A. Krasney, A. Ellis, B. McDonald, C. Marconi, and P. Cerretelli. 1985. Cardiac output and muscle blood flow in exercising dogs. Respir. Physiol. 61:317-326.

25. Iversen, P.O., and G. Nicolaysen. 1989. Heterogenous blood flow distribution within single skeletal muscles in the rabbit: role of vasomotion, sympathetic nerve activity and effect of vasodilation. Acta Physiol. Scand. 137:125133.

26. Iversen, P.O., and G. Nicolaysen. 1995. High correlation of fractals for regional blood flows among resting and exercising skeletal muscle. Am. J. Physiol. 269:H7-H13.

27. Duling, B.R., and D.H. Damon. 1987. An examination of the measurement of flow heterogeneity in striated muscle. Circ. Res. 60:1-13.

28. Clark, M.G., E.Q. Colquhoun, S. Rattigan, K.A. Dora, T.P.D. Elder- shaw, J.L. Hall, and J. Ye. 1995. Vascular and endocrine control of muscle metabolism. Am. J. Physiol. 268:E797-E812.

29. Harrison, D.K., S. Birkenhake, S.K. Knauf, and M. Kessler. 1990. Loca oxygen supply and blood flow regulation in contracting muscle in dogs and rabbits. J. Physiol. 422:227-243.

30. Damon, D.H., and B.R. Duling. 1985. Evidence that capillary perfusion heterogeneity is not controlled in striated muscle. Am. J. Physiol. 249:H386H392.

31. Iversen, P.O., M. Standa, and G. Nicolaysen. 1989. Marked regional heterogeneity in blood flow within a single skeletal muscle at rest and during exercise hyperaemia in the rabbit. Acta Physiol. Scand. 136:17-28.

32. Potter, R.F., and A.C. Groom. 1983. Capillary diameter and geometry in cardiac and skeletal muscle studied by means of corrosion casts. Microvasc. Res. 25:68-84.

33. Rattigan, S., K.A. Dora, E.Q. Colquhoun, and M.G. Clark. 1993. Serotonin-mediated acute insulin resistance in the perfused rat hindlimb but not in incubated muscle: a role for the vascular system. Life Sci. 53:1545-1555.

34. Rattigan, S., K.A. Dora, E.Q. Colquhoun, and M.G. Clark. 1995. Inhibition of insulin-mediated glucose uptake in rat hindlimb by an $\alpha$-adrenergic vascular effect. Am. J. Physiol. 268:E305-E311.

35. Alenius, S., and U. Ruotsalainen. 1997. Bayesian image reconstruction for emission tomography based on median root prior. Eur. J. Nucl. Med. 24 258-265.

36. Mokan, M., and J.E. Gerich. 1992. A simple insulin infusion algorithm for establishing and maintaining overnight near-normoglycemia in type I and type II diabetes. J. Clin. Endocrinol. Metab. 74:943-945.

37. DeFronzo, R.A., J.D. Tobin, and R. Andres. 1979. Glucose clamp technique: a method for quantifying insulin secretion and resistance. Am. J. Physiol. 237:E214-E223.

38. Stæhr, P., O. Hother-Nielsen, K. Levin, and H. Beck-Nielsen. 1994. Is hepatic insulin resistance a major feature of NIDDM patients with peripheral insulin resistance? Diabetes. 37(Suppl. 1):136a. (Abstr.)

39. Hother-Nielsen, O., J.E. Henriksen, J.J. Holst, and H. Beck-Nielsen. 1996. Effects of insulin on glucose turnover rates in vivo: isotope dilution versus constant specific activity technique. Metabolism. 45:82-91.

40. Crouzel, C., J. Clark, C. Brihaye, B. Långström, C. Lemaire, G. Meyer, B. Nebeling, and S. Stone-Elander. 1993. Radiochemistry automation for PET. In Radiopharmaceuticals for Positron Emission Tomography. G. Stöcklin and V. Pike, editors. Kluwer Academic Publishers Group, Dordrecht, The Netherlands. 45-90.

41. Hamacher, K., H.H. Coenen, and G. Stöcklin. 1986. Efficient stereospecific synthesis of no-carrier-added $2-\left[{ }^{18} \mathrm{~F}\right]$-fluoro-2-deoxy-D-glucose using aminopolyether supported nucleophilic substitution. J. Nucl. Med. 27:235-238.

42. Spinks, T.J., T. Jones, M.C. Gilardi, and J.D. Heather. 1988. Physical performance of the latest generation of commercial positron scanner. IEEE T. Nucl. Sci. 35:721-725.

43. Ter-Pogossian, M.M., M.E. Phelps, G.L. Brownell, J.R. Cox, D.O. Davis, and R.G. Evens. 1977. Reconstruction tomography in diagnostic radiology and nuclear medicine. University Park Press, Baltimore.

44. Kety, S.S., and C.F. Schmidt. 1945. The determination of cerebral blood flow in man by the use of nitrous oxide in low concentrations. Am. J. Physiol. 143:53-66.

45. Iida, H., I. Kanno, S. Miura, M. Murakami, K. Takahashi, and K. Uemura. 1986. Error analysis of a quantitative cerebral blood flow measurement using $\mathrm{H}_{2}{ }^{15} \mathrm{O}$ autoradiography and positron emission tomography, with respect to the dispersion of the input function. J. Cereb. Blood Flow Metabol. 6:536545

46. Howard, B.E., M.D. Ginsberg, W.R. Hassel, A.H. Lockwood, and P. Freed. 1983. On the uniqueness of cerebral blood flow measured by the in vivo autoradiographic strategy and positron emission tomography. J. Cereb. Blood Flow Metabol. 2:99-108.

47. Sokoloff, L., M. Reivich, C. Kennedy, M.H. Des Rosiers, C.S. Patlak, K.D. Pettigrew, O. Sakurada, and M. Shinohara. 1977. The $\left[{ }^{14} \mathrm{C}\right]$ deoxyglucose method for the measurement of local cerebral glucose utilization: theory, procedure, and normal values in the conscious and anesthetized albino rat. J. Neurochem. 28:897-916.

48. Nuutila, P., V.A. Koivisto, J. Knuuti, U. Ruotsalainen, M. Teräs, M Haaparanta, J. Bergman, O. Solin, L.-M. Voipio-Pulkki, U. Wegelius, and H. Yki-Järvinen. 1992. Glucose-free fatty acid cycle operates in human heart and skeletal muscle in vivo. J. Clin. Invest. 89:1767-1774.

49. Vicini, P., R.C. Bonadonna, T. Utriainen, P. Nuutila, M. Raitakari, H. Yki-Järvinen, and C. Cobelli. 1997. Estimation of blood flow heterogeneity distribution in human skeletal muscle from positron emission tomography data. Ann. Biomed. Eng. 25:906-910.

50. Raitakari, M., P. Nuutila, U. Ruotsalainen, H. Laine, M. Teräs, H. Iida, S. Mäkimattila, T. Utriainen, V. Oikonen, H. Sipilä, et al. 1996. Evidence for dissociation of insulin stimulation of blood flow and glucose uptake in human skeletal muscle. Studies using $\left[{ }^{15} \mathrm{O}\right] \mathrm{H}_{2} \mathrm{O},\left[{ }^{18} \mathrm{~F}\right]$ fluoro-2-deoxy-D-glucose, and positron emission tomography. Diabetes. 45:1471-1477.

51. Groeneveld, A.B.J., A.A. van Lambalgen, G.C. van den Bos, J.J.P. Nauta, and L.G. Thijs. 1992. Metabolic vasodilatation with glucose-insulinpotassium does not change the heterogenous distribution of coronary blood 
flow in the dog. Cardiovasc. Res. 26:757-764.

52. Natali, A., R. Bonadonna, D. Santoro, A.Q. Galvan, S. Baldi, S. Frascerra, C. Palombo, S. Ghione, and E. Ferrannini. 1994. Insulin resistance and vasodilation in essential hypertension. Studies with adenosine. J. Clin. Invest. 94:1570-1576.

53. Laakso, M., S.V. Edelman, G. Brechtel, and A.D. Baron. 1990. Decreased effect of insulin to stimulate skeletal muscle blood flow in obese man. A novel mechanism for insulin resistance. J. Clin. Invest. 85:1844-1852.

54. Utriainen, T., R. Malmström, S. Mäkimattila, and H. Yki-Järvinen. 1995. Methodological aspects, dose-response characteristics and causes of interindividual variation in insulin stimulation of limb blood flow in normal subjects. Diabetologia. 38:555-564.

55. Steinberg, H.O., H. Chaker, R. Leaming, A. Johnson, G. Brechtel, and A.D. Baron. 1996. Obesity/insulin resistance is associated with endothelial dysfunction. Implications for the syndrome of insulin resistance. J. Clin. Invest. 97: 2601-2610.

56. Steinberg, H.O., G. Brechtel, A. Johnson, N. Fineberg, and A.D. Baron. 1994. Insulin-mediated skeletal muscle vasodilation is nitric oxide dependent. A novel action of insulin to increase nitric oxide release. J. Clin. Invest. 94:11721179.

57. Scherrer, U., D. Randin, P. Vollenweider, L. Vollenweider, and P. Nicod. 1994. Nitric oxide release accounts for insulin's vascular effects in humans. J. Clin. Invest. 94:2511-2515.

58. Tesfamariam, B., M.L. Brown, and R.A. Cohen. 1991. Elevated glucose impairs endothelium-dependent relaxation by activating protein kinase C. $J$. Clin. Invest. 87:1643-1648.

59. Mäkimattila, S., A. Virkamäki, P.-H. Groop, J. Cockcroft, T. Utriainen, J. Fagerudd, and H. Yki-Järvinen. 1996. Chronic hyperglycemia impairs endothelial function and insulin sensitivity via different mechanisms in insulindependent diabetes mellitus. Circulation. 94:1276-1282.

60. Iversen, P.O., and G. Nicolaysen. 1991. Local blood flow and glucose uptake within resting and exercising rabbit skeletal muscle. Am. J. Physiol. 260: H1795-H1801.

61. James, D.E., A.B. Jenkins, and E.W. Kraegen. 1985. Heterogeneity of insulin action in individual muscles in vivo: euglycemic clamp studies in rats. Am. J. Physiol. 248:E567-E574.

62. Johnson, M.A., J. Polgar, D. Weightman, and D. Appleton. 1973. Data on the distribution of fibre types in thirty-six human muscles. An autopsy study. J. Neurol. Sci. 18:111-129.

63. Elder, G.C.B., K. Bradbury, and R. Roberts. 1982. Variability of fiber type distributions within human muscles. J. Appl. Physiol. 53:1473-1480.

64. Andersen, P. 1975. Capillary density in skeletal muscle of man. Acta Physiol. Scand. 95:203-205.

65. Lillioja, S., A.A. Young, C.L. Culter, J.L. Ivy, W.G.H. Abbott, J.K. Zawadzki, H. Yki-Järvinen, L. Christin, T.W. Secomb, and C. Bogardus. 1987. Skeletal muscle capillary density and fiber type are possible determinants of in vivo insulin resistance in man. J. Clin. Invest. 80:415-424.

66. Hickey, M.S., J.O. Carey, J.L. Azevedo, J.A. Houmard, W.J. Pories, R.G. Israel, and G.L. Dohm. 1995. Skeletal muscle fiber composition is related to adiposity and in vitro glucose transport rate in humans. Am. J. Physiol. 268: E453-E457.

67. Utriainen, T., A. Holmäng, P. Björntorp, S. Mäkimattila, A. Sovijärvi, H. Lindholm, and H. Yki-Järvinen. 1996. Physical fitness, muscle morphology and insulin-stimulated limb blood flow in normal subjects. Am. J. Physiol. 270 E905-E911.

68. Vollenweider, P., L. Tappy, D. Randin, P. Schneiter, E. Jéquier, P. Nicod, and U. Scherrer. 1993. Differential effects of hyperinsulinemia and carbohydrate metabolism on sympathetic nerve activity and muscle blood flow in humans. J. Clin. Invest. 92:147-154.

69. Selberg, O., W. Burchert, J. v d Hoff, G.J. Meyer, H. Hundeshagen, E. Radoch, H.-J. Balks, and M.J. Müller. 1993. Insulin resistance in liver cirrhosis. Positron-emission tomography scan analysis of skeletal muscle glucose metabolism. J. Clin. Invest. 91:1897-1902.

70. Kelley, D.E., M.A. Mintun, S.C. Watkins, J.A. Simoneau, F. Jadali, A. Fredrickson, J. Beattie, and R. Thériault. 1996. The effect of non-insulindependent diabetes mellitus and obesity on glucose transport and phosphorylation in skeletal muscle. J. Clin. Invest. 97:2705-2713.

71. Grill, V., M. Gutniak, O. Björkman, M. Lindqvist, S. Stone-Elander, R.J. Seitz, G. Blomqvist, P. Reichard, and L. Widén. 1990. Cerebral blood flow and substrate utilization in insulin-treated diabetic subjects. Am. J. Physiol. 258 E813-E820.

72. Kahn, B.B. 1992. Facilitative glucose transporters: regulatory mechanisms and dysregulation in diabetes. J. Clin. Invest. 89:1367-1374.

73. Wilson, J.E. 1995. Hexokinases. Rev. Physiol. Biochem. Pharmacol. 126: 65-198.

74. Saccomani, M.P., R.C. Bonadonna, D.M. Bier, R.A. DeFronzo, and C. Cobelli. 1996. A model to measure insulin effects on glucose transport and phosphorylation in muscle: a three-tracer study. Am. J. Physiol. 270:E170E185. 